\title{
Jejunal amyloidosis: A rare cause of severe gastrointestinal bleeding
}

\author{
Alan Hoi Lun Yau BSc ${ }^{1}$, lan Scott Cornell MD FRCPC ${ }^{2}$, Justin Cheung MD FRCPC 3
}

\section{CASE PRESENTATION}

An 81-year-old Jamaican woman presented with melena and severe anemia, and a hemoglobin level of $47 \mathrm{~g} / \mathrm{L}$ (normal range $115 \mathrm{~g} / \mathrm{L}$ to $160 \mathrm{~g} / \mathrm{L}$ ). A gastroscopy and colonoscopy were negative for any lesions. Duodenal biopsies were normal. A subsequent computed tomography scan of the abdomen with contrast showed diffuse thickening from the jejunum to the distal small bowel and a small area of active bleeding in the mid small bowel. A technetium-99m red blood cell scan demonstrated active bleeding in the proximal jejunum. Push enteroscopy (120 cm to $150 \mathrm{~cm}$ below incisor) revealed mild diffuse friability starting from the proximal jejunum, as well as erosions, nodularities, polypoid protrusions and valvulae conniventes thickening in the remaining jejunum (Figures $1 \mathrm{~A}$ and $1 \mathrm{~B}$ ). Jejunal biopsies showed extensive amyloid deposition in the lamina propria and submucosa, with Congo red stain demonstrating apple-green birefringence under polarized light (Figure 2), and hematoxylin counterstain revealing amorphous, salmon-pink, sparsely cellular hyaline material (Figure 3). Serum protein electrophoresis, immunofixation and a serum-free light chain assay confirmed the presence of monoclonal immunoglobulin G lambda paraprotein. The patient was transfused with packed red blood cells as needed (average one unit per day), and treated with bortezomib and dexamethasone for primary amyloidosis. By day 17 of hospitalization, the bleeding had resolved and the patient was subsequently discharged without any further bleeding episodes.

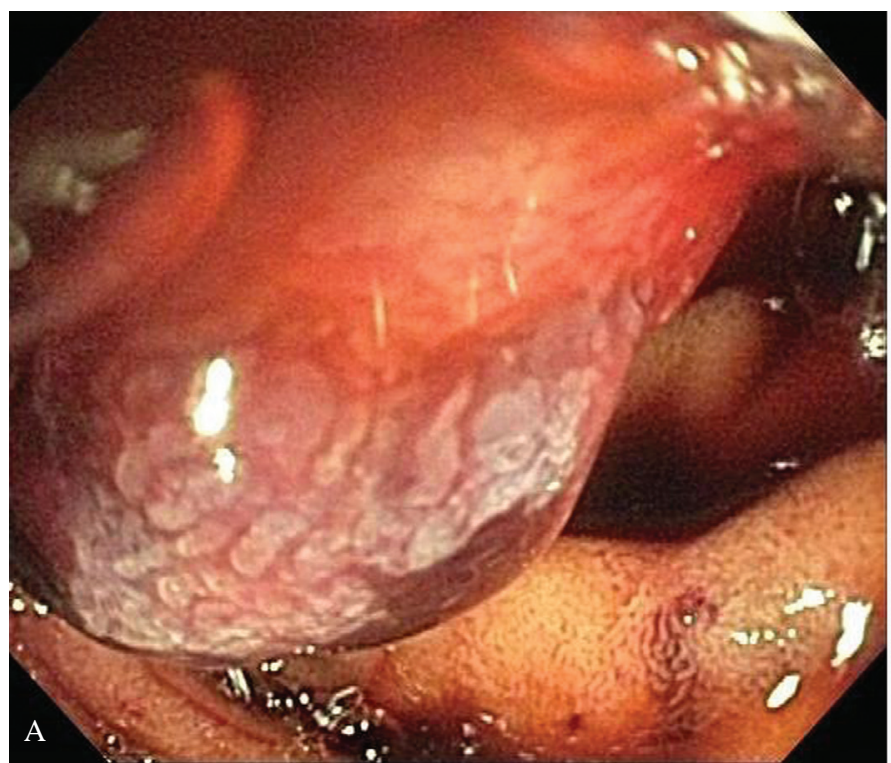

\section{DISCUSSION}

Amyloidosis is a multisystem disease characterized by extracellular deposition of abnormal protein fibrils in various tissues and organs. The protein fibrils are derived from monoclonal immunoglobulin light chains in primary amyloidosis (AL), acute phase reactant serum amyloid $\mathrm{A}$ in secondary amyloidosis (AA), and beta 2 -microglobulin in dialysis-related amyloidosis $(A \beta 2 \mathrm{~m})$. Clinical manifestations in amyloidosis are variable, but the heart and kidneys are most commonly involved. Gastrointestinal symptoms due to bleeding, dysmotility and malabsorption are present in up to $60 \%$ of AA (1), but in only $1 \%$ of AL (2). The diagnosis of amyloidosis can only be confirmed by tissue biopsy because endoscopic and radiologic findings are nonspecific. Therapy is directed at the underlying cause in AL (plasma cell dyscrasia) and AA (infection, inflammation and malignancy), whereas treatment in $A \beta 2 \mathrm{~m}$ involves alteration of dialysis mode or consideration of renal transplantation (3).

Severe gastrointestinal bleeding rarely occurs as the sole or initial manifestation of systemic amyloidosis (4). Mechanisms by which hemorrhage occurs in gastrointestinal amyloidosis have been postulated, including intestinal ischemia, necrotic ulceration, mucosal tearing, vascular fragility, abnormal platelet aggregation, and factor IX and X deficiencies $(5,6)$. In addition to supportive care for bleeding, treatment must be tailored to the specific type of amyloidosis, as determined by endoscopy and histology. Endoscopy classically shows polypoid protrusions and valvulae conniventes thickening in AL; a

Figure 1) A and B Endoscopic views of amyloidosis showing a markedly abnormal jejunum with edema, erythema, friability, polypoid protrusions and valvulae conniventes thickening

${ }^{1}$ Department of Medicine; ${ }^{2}$ Division of Pathology; ${ }^{3}$ Division of Gastroenterology, University of British Columbia, Royal Columbian Hospital,

New Westminster, British Columbia

Correspondence: Dr Justin Cheung, Department of Gastroenterology, Royal Columbian Hospital, 410-301 East Columbia Street,

New Westminster, British Columbia V3L 3W5. Telephone 604-525-0155, fax 604-525-1699, e-mail justa48@hotmail.com

Received for publication December 22, 2011. Accepted December 29, 2011 


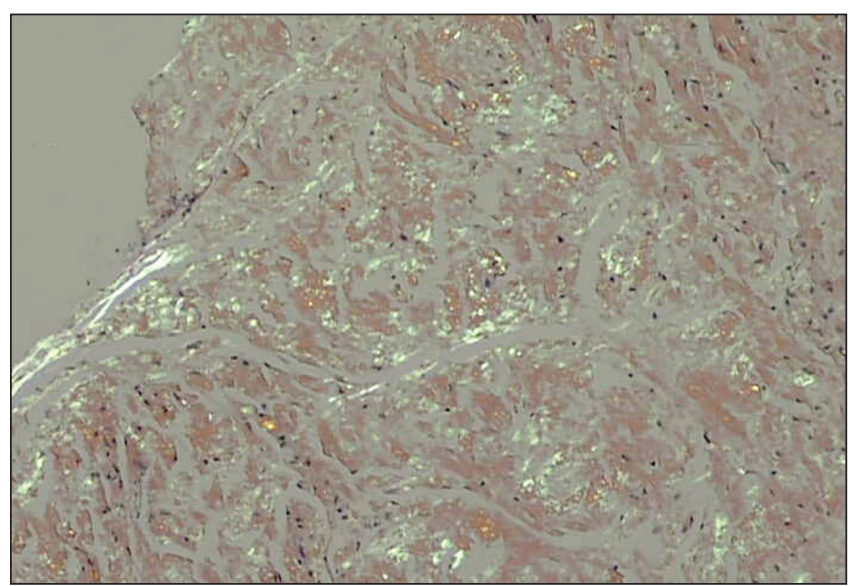

Figure 2) Jejunal biopsy demonstrating apple-green birefringence of amyloid deposits under polarized light (Congo red stain, original magnification $\times 100$ )

coarse mucosal pattern with a fine granular appearance in AA; and intestinal dilation in $A \beta 2 \mathrm{~m}$ (7). Histology typically reveals amyloid deposition in muscularis mucosae, submucosa and muscularis propria in AL; infiltration of lamina propria and myenteric plexus in AA; and involvement of muscularis propria in $A \beta 2 \mathrm{~m}(7,8)$. Knowledge of

\section{REFERENCES}

1. Okuda Y, Takasugi K, Oyama T, Onuma M, Oyama H. Amyloidosis in rheumatoid arthritis - clinical study of 124 histologically proven cases. Ryumachi 1994;34:939.

2. Menke DM, Kyle RA, Fleming CR, Wolfe JT 3rd, Kurtin PJ, Oldenburg WA. Symptomatic gastric amyloidosis in patients with primary systemic amyloidosis. Mayo Clin Proc 1993;68:763.

3. Gorevic PD, Schur PH, Romain PL. An overview of amyloidosis. In: UpToDate, Basow DS, ed. UpToDate, Waltham: 2011.

4. Jarnum S. Gastrointestinal hemorrhage and protein loss in primary amyloidosis. Gut 1965;6:14-8.

5. Chang HS, Myung SJ, Yang SK, et al. Massive small bowel bleeding in a patient with amyloidosis. Gastrointest Endosc 2004;59:126-9.

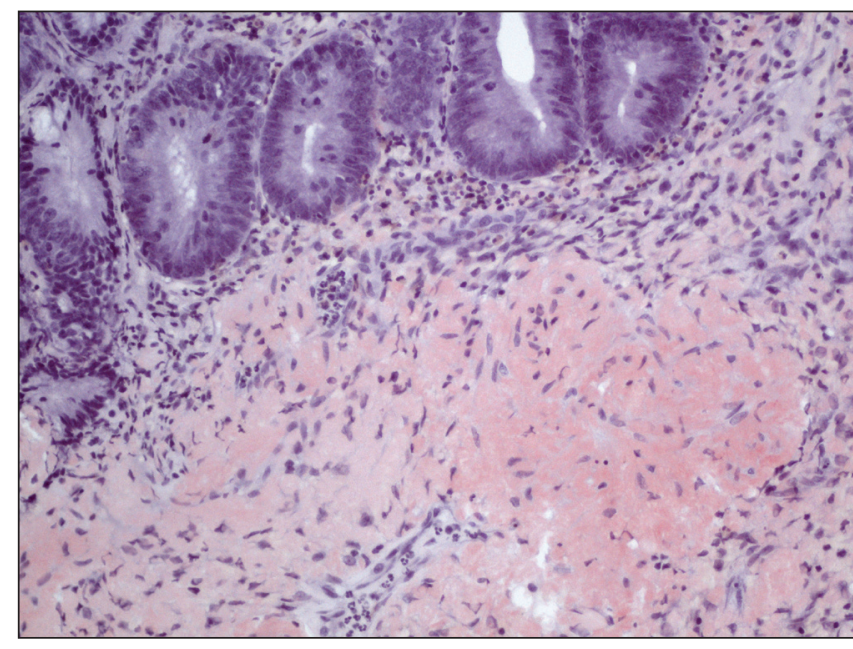

Figure 3) Jejunal specimen revealing extensive amyloid deposition of amorphous, salmon-pink, sparsely cellular, hyaline material within the submucosa and focally within the lamina propria (hematoxylin counterstain, original magnification $\times 200$ )

the characteristic endoscopic appearance and histological findings of gastrointestinal amyloidosis is essential in making a timely and accurate diagnosis.

6. Kaiserling E, Kröber S. Massive intestinal hemorrhage associated with intestinal amyloidosis. An investigation of underlying pathologic processes. Gen Diagn Pathol 1995;141:147-54.

7. Tada S, Iida M, Yao T, et al. Endoscopic features in amyloidosis of the small intestine: Clinical and morphologic differences between chemical types of amyloid protein. Gastrointest Endosc 1994:40:45-50.

8. Tada S, Iida M, Yao T, Kitamoto T, Yao T, Fujishima M. Intestinal pseudo-obstruction in patients with amyloidosis: Clinicopathologic differences between chemical types of amyloid protein. Gut 1993;34:1412-7.

The Canadian Journal of Gastroenterology is now considering a limited number of submissions for IMAGE OF THE MONTH. These are based on endoscopic, histological, radiological and/or patient images, which must be anonymous with no identifying features visible. The patient must consent to publication and the consent must be submitted with the manuscript. All manuscripts should be practical and relevant to clinical practice, and not simply a case report of an esoteric condition. The text should be brief, structured as CASE PRESENTATION and DISCUSSION, and not more than 700 words in length. A maximum of three images can be submitted and the number of references should not exceed five. The submission may be edited by our editorial team.

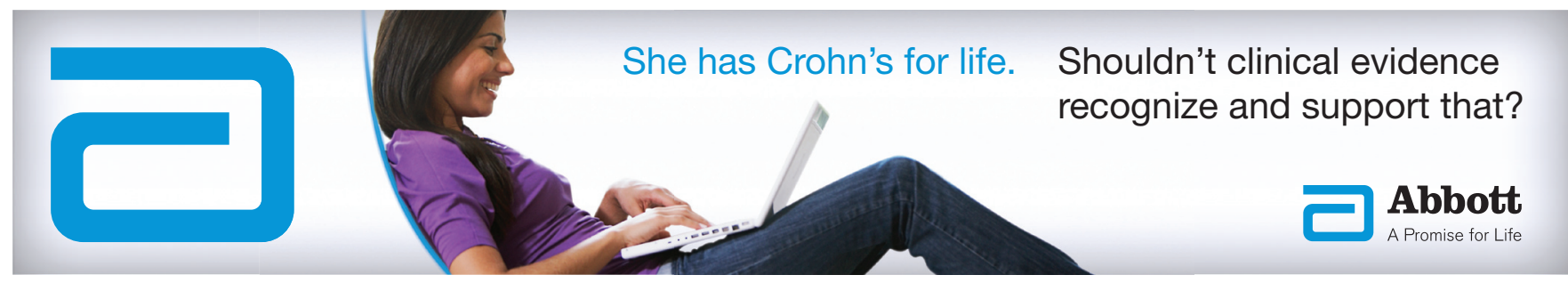




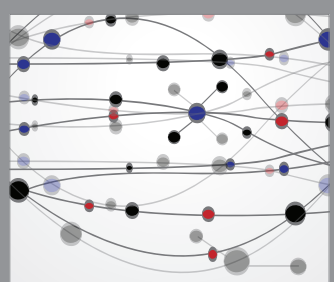

The Scientific World Journal
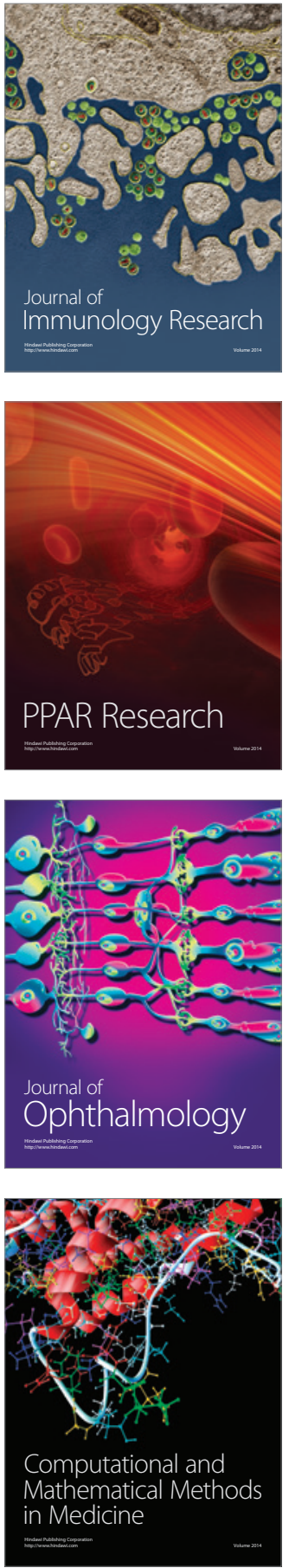

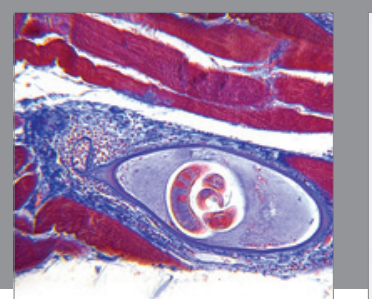

Gastroenterology Research and Practice

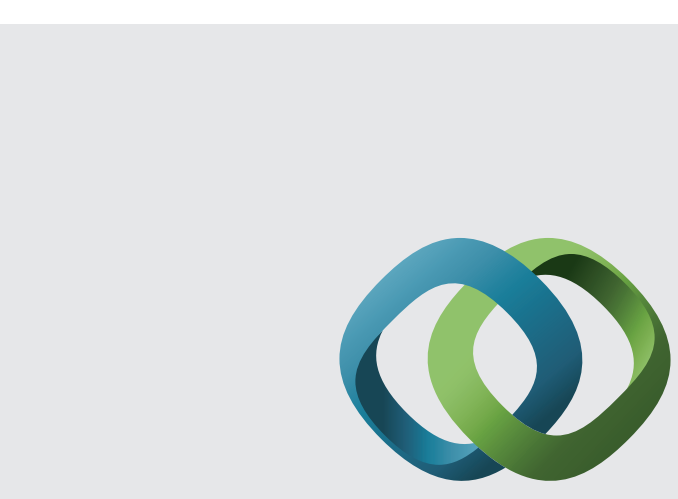

\section{Hindawi}

Submit your manuscripts at

http://www.hindawi.com
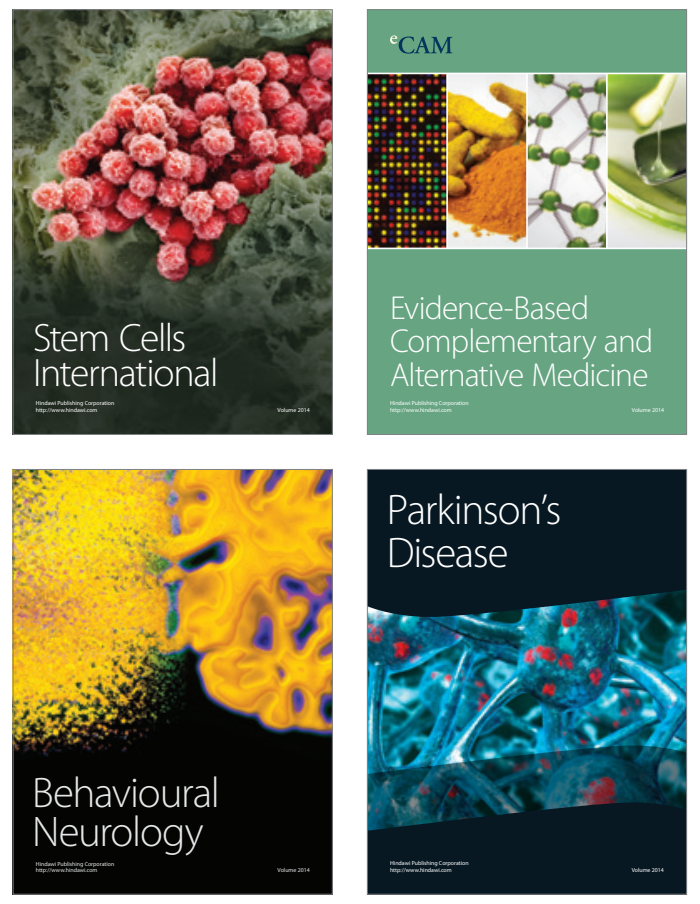
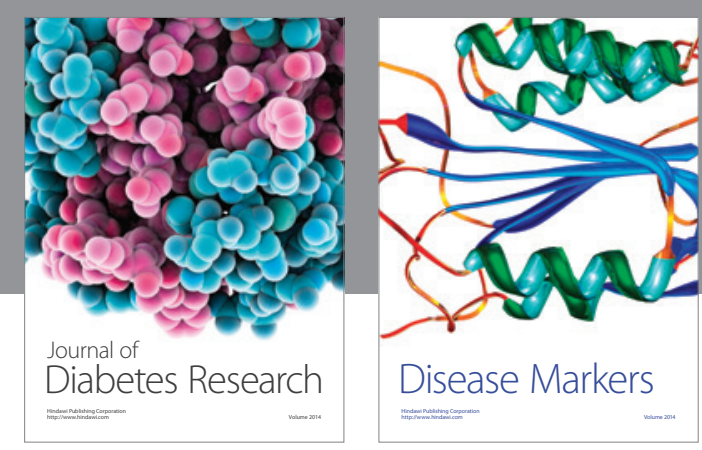

Disease Markers
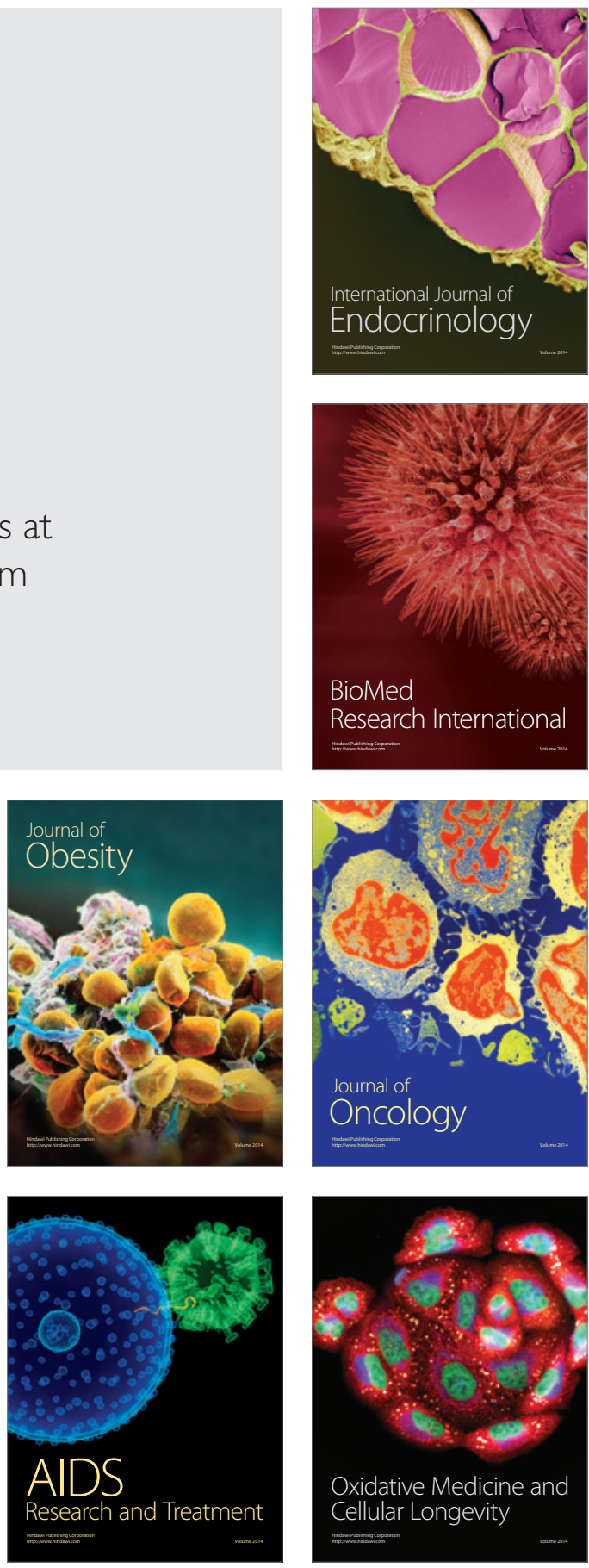